\title{
On the early history of the Finnish Meteorological Institute
}

\author{
H. Nevanlinna \\ Finnish Meteorological Institute, P.O. Box 503, 00101 Helsinki, Finland \\ Correspondence to: H. Nevanlinna (heikki.nevanlinna@gmail.com)
}

Received: 17 January 2014 - Accepted: 14 March 2014 - Published: 28 March 2014

\begin{abstract}
This article is a review of the foundation (in 1838) and later developments of the Helsinki (Finland) magnetic and meteorological observatory, today the Finnish Meteorological Institute (FMI). The main focus of the study is in the early history of the FMI up to the beginning of the 20th century.

The first director of the observatory was Physics Professor Johan Jakob Nervander (1805-1848). He was a famous person of the Finnish scientific, academic and cultural community in the early decades of the 19th century.

Finland was an autonomously part of the Russian Empire from 1809 to 1917, but the observatory remained organizationally under the University of Helsinki, independent of Russian scientific institutions, and funded by the Finnish Government. Throughout the late-19th century the Meteorological Institute was responsible of nationwide meteorological, hydrological and marine observations and research. The observatory was transferred to the Finnish Society of Sciences and Letters under the name the Central Meteorological Institute in 1881. The focus of the work carried out in the Institute was changed gradually towards meteorology. Magnetic measurements were still continued but in a lower level of importance.

The culmination of Finnish geophysical achievements in the 19th century was the participation to the International Polar Year programme in 1882-1883 by setting up a full-scale meteorological and magnetic observatory in Sodankylä, Lapland.
\end{abstract}

\section{Introduction}

In the beginning of the 19th century, when magnetic and electrical phenomena were found to be closely related to each other, a new physical science, electromagnetism, was born. In 1820 Hans Christian Örsted (1777-1851) could prove this connection by a simple physical experiment in which electric currents cause forces that deflect a magnetic needle. Within a few years, Ampére, Faraday and other scientists discovered more basic laws of electromagnetism as well as electrodynamics. These findings roused enormous interest in the scientific community of the early 19th century. Especially studies in geomagnetism, the new concept of the magnetic induction was adopted as an improved paradigm that would guide scientists towards the solution of the old riddle: what is the cause of Earth's permanent magnetism? Earth could be a huge electromagnet sustained by magnetic induction processes deep inside it.
It was known in the early 19th century that daily variation of geomagnetic declination followed the local solar time, showing largest deviation near midday. Because the occurrence time of daily temperature maximum was close to the magnetic one, it was speculated that diurnal magnetic variations are caused by temperature variations through thermally induced earth currents. This was a reason why magnetic and meteorological observations were combined in the same observational programme, as was the common practice throughout the 19th century. For that purpose systematic and coordinated magnetic and meteorological recordings were found necessary in different parts of Earth and in various timescales.

In order to better understand the hypothesized relationships between geomagnetic variations and meteorological ones, Alexander von Humboldt (1769-1859), the leading scholar in natural sciences of the time, made a far-reaching 
initiative to the international scientific community in the late 1820s (Malin and Barraclough, 1991). He proposed that a global network of observatories should be established for monitoring changes in the geomagnetic field and meteorological parameters with similar instruments and by uniform observational routines (Barraclough et al., 1992; Stern, 2002). His plan brought a quick response in the scientific community. In a short time, in the 1830 s and 1840 s about 30 observatories were set up around the world mostly by French, German, Russian and UK scientific authorities (Cawood, 1977; Lockwood, 2013) (Fig. 1). Another important enterprise in the field of geomagnetism was "The Magnetic Union" (1834-1841) founded by Gauss and Weber in Göttingen, Germany. The Union organized coordinated magnetic observatory campaigns in Europe at several tens of sites. Gauss and Weber invented new types of geomagnetic instruments for the geomagnetic community (Gauss, 1838; Hentschel, 2007; Lockwood, 2013). The foundation of the magnetic and meteorological observatory in Helsinki in 1838 was a manifestation of this large-scale international co-operation.

The enthusiasm among scientists, inspired by the new electromagnetic science, launched a rapid development in geomagnetism, both in theory and practical measurements. However, traditions of simultaneous meteorological observations go back further in time to the late-18th century. The Palatine Meteorological Society in Mannheim, Germany, organized an international programme of synoptic meteorological observations with calibrated instruments. This was perhaps the most important early undertaking in the branch of meteorology. Almost 40 stations, mostly in Europe, were participating in this scientific project for 15 years (1780-1795) (Cassidy, 1985). The principles of systematic meteorological observations introduced by the Mannheim Society were rediscovered in the beginning of the 19th century after the Napoleonic wars when international scientific co-operation started again in Europe. Magnetic and meteorological observations were combined in a systematic observational programme with similar instruments. Until the late-19th century the observatories were thus generally called as "Magneticmeteorological observatories".

\section{Geomagnetism starts in Finland}

On 28 March 1838, Nicholas I, the Emperor of Russia, signed a decree by which a magnetic observatory was founded at the University of Helsinki. This was the beginning of the present day Finnish Meteorological Institute more than 175 years ago. In addition, funds were allotted for the building of the observatory for magnetic and meteorological observations. The observatory was set up in the corner of the Kaisaniemi park, which is in the very centre of present day Helsinki.
The initiative of the founding of the Helsinki observatory came from Russia. Adolf Kupffer (1799-1865) from the Russian Science Academy suggested already in 1836 that the University of Helsinki should set up a magnetic observatory in order to complete the Russian observatory network (Nevanlinna and Häkkinen, 2010). Under Kupffer's leadership, seven geomagnetic observatories were established in Russia in 1830-1840. Kupffer was well acquainted with Gauss and von Humboldt and he was an active member of the "Göttingen Magnetic Union".

The first director of the magnetic observatory was Physics Professor Johan Jakob Nervander (1805-1848) (Fig. 2), who was a close colleague of Kupffer. He was a famous person of the Finnish scientific, academic and cultural community in the early decades of the 19th century (Simojoki, 1978; Holmberg and Nevanlinna, 2005). For 4 years (1832-1836) Nervander visited leading scientific institutes in Europe, i.e. Göttingen where he studied geomagnetism supervised by Gauss and Weber (Holmberg, 1992).

Nervander's doctoral thesis dealt with a device called today a galvanometer. In his time, the instrument was known as tangent bussole, as the tangent of the deviation angle of the sensor magnet was proportional to the current to be measured. The European scientific community appreciated Nervander's version of the galvanometer, and a description of it was published in the annals of the French Academy of Science in 1834 (Nervander, 1834; Holmberg, 1992). A modern replica of his galvanometer has been constructed by Venermo and Sihvola (2008).

Nervander actively took part of the climatological and phenological programme of Finland that started in 1846 and has continued since then. He also studied climatology, especially the question of how sunspots may affect atmospheric temperatures in connection with the discovery of the cyclic behaviour of the appearance of sunspots introduced by Schwabe in 1844 (Stern, 2002). Nervander's scientific works won a prize from the Russian Science Academy in St. Petersburg.

Nervander can be considered the founding father of Finnish geomagnetic research, as well as one of the early pioneers in the research of solar influence on the terrestrial weather and climate. He was the first scientist in Finland who studied electromagnetism and made significant scientific contributions in that sector of physics (Nevanlinna, 2005).

\section{The magnetic observatory of Helsinki}

The buildings and instrumentation of the Helsinki magnetic observatory were completed in 1841 (Fig. 3) but training of the observers and installation of the equipment lasted a few years. The staff of the observatory started regular observations on 1 July 1844. During the first years, readings of magnetic field and meteorological parameters (temperature, 


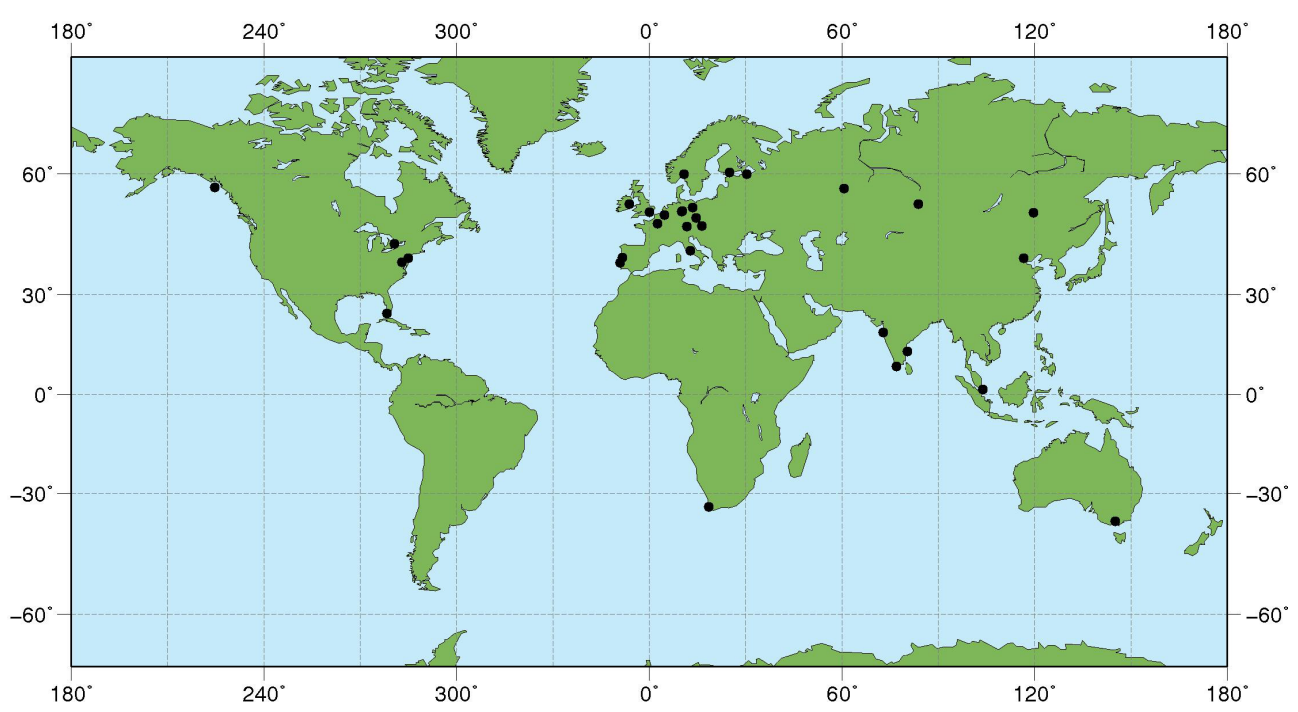

Figure 1. Distribution of magnetic and meteorological observatories in 1850 (Nevanlinna and Häkkinen, 2010). The number of observatories was 30 . Today, there are some 200 observatories around the world.

air pressure, precipitation, and wind direction and force) were taken several times hourly around the clock every day throughout the year. Typically, the number of daily observations was about 1000 . There were 12 students making the observations manually without any aid of automatic recording instruments (not yet invented). The magnetic observatory was the biggest and most expensive institution of the Helsinki University.

The instrumentation and the observatory methods were adopted from the Göttingen observatory. Three magnetic components of the magnetic vector were observed: horizontal intensity $(H)$, declination $(D)$, and the vertical component $(Z)$. Observations were made six times per hour, and hourly after 1856.

Although Nervander died suddenly in 1848 , observations continued at the observatory until 1912 , when the electric tram traffic in the observatory's neighbourhood disturbed the measurements making the sensitive magnetic recordings useless. Unfortunately, only the observations carried out during Nervander's leadership 1844-1848 were treated for further analysis and printed in yearbooks. However, all of the observation results made in the observatory for almost 70 years had been carefully deposited, waiting for possible later data treatment. Magnetic and meteorological observations collected in the Helsinki observatory during the 1844-1912 period consist of several millions of single data values of various geophysical parameters. The quality of the observations is good. The resolution of times series of the data is mostly 1 hour. Long-term meteorological data (e.g. temperature) are important sources of local atmospheric conditions for studies e.g. climate change. In the Finnish climate database the temperature observations from the Helsinki observatory represent the longest continuous observation series in Finland cov- ering almost 170 years. Its scientific value has been proven in many climatology studies (e.g. Tietäväinen et al., 2010).

Unpublished original magnetic observations from the Helsinki observatory were converted in electronic form in the early 1990s by the magnetism team of the Finnish Meteorological Institute (Nevanlinna, 2004). The data consist of about 2 million single magnetic field (declination and horizontal force) observations from 1844 to 1912 . This data set gives a homogenous time series of geomagnetic field variation covering a time period from which only few reliable observatory data series are available (Lockwood, 2013; Lockwood et al., 2013). Long time series of old geomagnetic data reveal variations in the space weather and space climate from epochs before the satellite era. By combining historical recordings with modern magnetic and satellite data, it has been possible to reconstruct behaviour of solar activity and solar wind parameters in the past (e.g. Svalgaard and Cliver, 2007; Lockwood et al., 2013).

Nervander's scientific career was short, but his influence on geophysical research in Finland was important. Without his energetic efforts in establishing the magnetic observatory in Helsinki, the advent of this modern scientific discipline in Finland would certainly have been greatly delayed. Nervander created traditions for geomagnetic observations and their treatment for magnetic yearbooks. Nervander did not have any students who continued his work after his death, although routine magnetic and meteorological observations were carried out on a regular basis. The new director of the observatory after Nervander was Henrik Gustaf Borenius (1802-1894). He was Nervander's son-in-law and well acquainted with the routines of the observatory. However, no changes or improvements in the observation practice were made during Borenius' directorship. When he retired in 


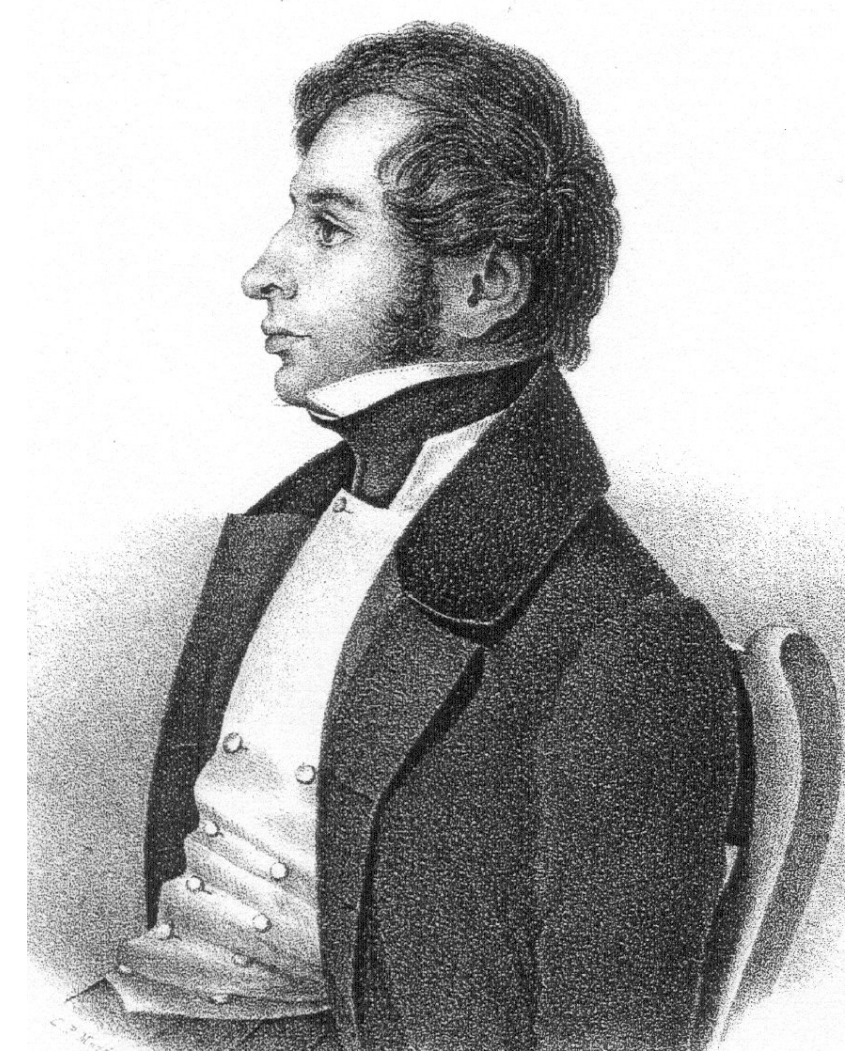

Figure 2. Johan Jakob Nervander (1805-1848), the first director of the Helsinki magnetic observatory, later the Finnish Meteorological Institute.

1880, the observatory was reorganized. Just prior to the start of International Polar Year (IPY), the administration of the magnetic-meteorological observatory of Helsinki was transferred from the Helsinki University to the Finnish Society of Sciences and Letters in 1881 . The academy was a governmental body with firm funding sources for various other geophysical tasks. The observatory was renamed Central Meteorological Institute which meant that the focus of the work carried out in the Institute was changed from magnetism towards meteorology. Magnetic measurements were continued but in a lower level of importance similarly to the observation programme in other European magnetic and meteorological observatories.

Political circumstances played certain role in the establishment of the Central Meteorological Institute. Under Borenius' leadership the Institute did not follow the general progress in weather services that was going on in Europe. This passivity could lead to the situation that the Finnish weather stations would gradually become absorbed into the Russian weather organization. The Society of Sciences did all it could to prevent this kind of development. The successor of Borenius, N. K. Nordenskiöld (1837-1889), suc-

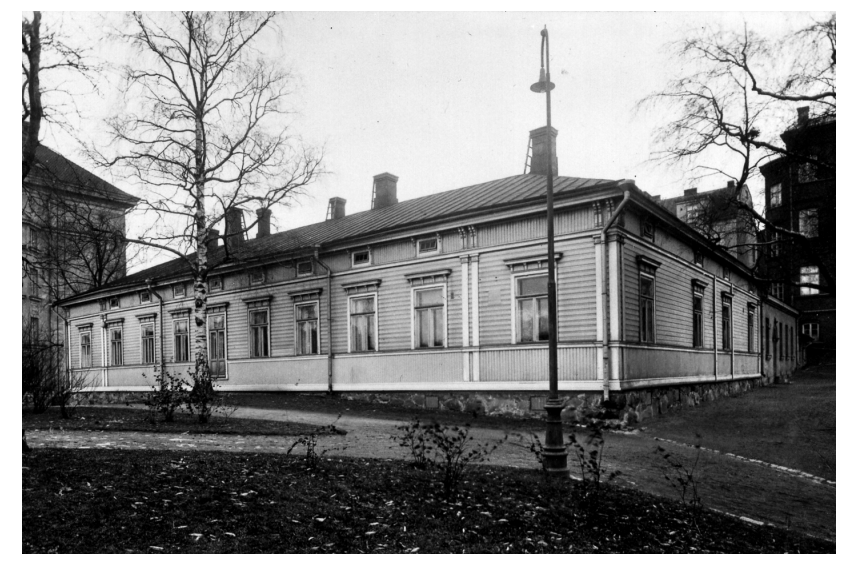

Figure 3. The main building of the Helsinki magnetic observatory in the 1930s. The building was set up in 1841 and demolished in the early 1960s. A new building for the Institute was set up in 1966 (Photo: FMI).

ceeded better as director because he was able to modernize the weather service work at the Central Meteorological Institute to meet international standards. Daily weather observations were published in Finnish journals since 1881 and new kinds of measurements were started; these were e.g. sea level observations with special instruments. These measurements were needed for seafaring but also for predictions of imminent floods in the City of St.Petersburg that was built in the seashore of the Gulf of Finland (Simojoki, 1978).

\section{Polar year 1882-1883}

The systematic worldwide magnetic and meteorological observations carried out in the first decades of the 19th century were started as a large international undertaking inspired by leading scholars like e.g. von Humboldt and Gauss. Later in the 19th century the interest of the geophysical community focused to the polar regions, which were largely unknown areas. These efforts culminated in the first International Polar Year (IPY) in 1882-1883. The main goal was the establishment of observation stations in the Arctic and Antarctic regions and recording magnetic and other geophysical, e.g. meteorological and auroral, measurements in a coordinated way. The Finnish contribution to auroral observations was mainly the works by Selim Lemström. His idea was that auroras are a manifestation of atmospheric electricity similar to ordinary lightnings. He made extensive experiments in Lapland for measuring hypothesized electric currents accompanied by auroral displays (e.g. Seppinen and Pellinen, 2009).

During the polar year a total of 12 countries established 14 stations, 12 in a circumpolar ring in the Arctic and 2 in the Antarctic. Each station carried out a standard, synchronized programme of observations for at least 1 year, the major focus being on meteorology and Earth magnetism. Supplementary programmes included studies ranging from 


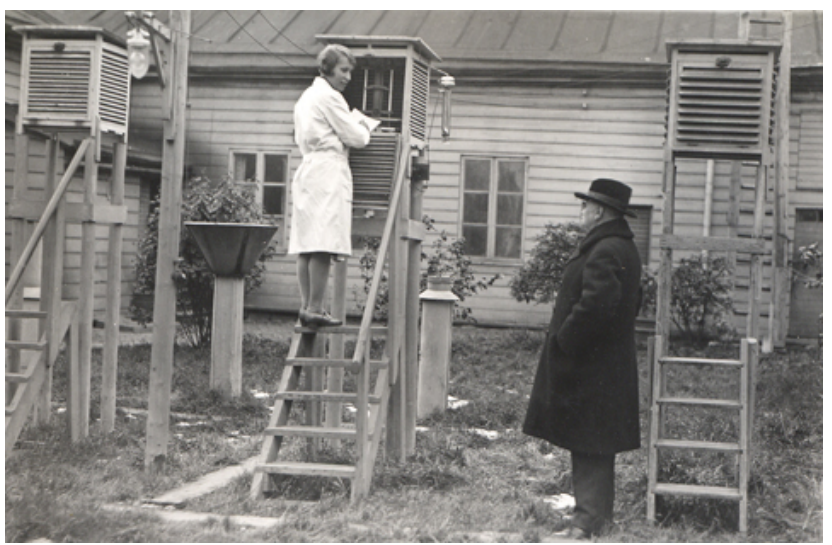

Figure 4. Weather station at the Finnish Meteorological Institute in Helsinki in the 1920s. The man in the right is Gustaf Melander (1861-1938), the director of the Institute 1908-1930 (Photo: FMI).

ornithology to soil temperatures to ethnography. The entire programme was coordinated by an International Polar Commission, chaired by Professor H. Wild from the Russian Central Physical Observatory in St. Petersburg (e.g. Barr, 2008).

The Finnish contribution to the IPY was the establishment of a full-scale geophysical observatory in Sodankylä, Lapland, inside the polar circle (Holmberg, 1992; Seppinen and Pellinen, 2009). Measurements included magnetic, meteorological and auroral variations. Finland was a participating member in the IPY programme although the country was a part of the Russian Empire. In this way, Finland could emphasize its national identity in the scientific community.

The Finnish IPY project was funded by governmental sources and managed by the Finnish Society of Sciences and Letters but the Central Meteorological Institute provided the instrumentation needed for fulfilment of the programme. The director of the whole project was Selim Lemström (18381904), professor of physics in Helsinki, but the local supervision of daily observations at Sodankylä was the responsibility of Ernst Biese (1856-1926), later the director of the Central Meteorological Institute.

All measurements were mainly hourly observations made throughout day and night during 1 year. The final results were published in three large volumes by Lemström and Biese (1886-1898) The Finnish polar year project was successfully fulfilled and Lemström's experiments of artificial northern lights were noted by the scientific community as well as other scientific results from the Sodankylä station (Seppinen and Pellinen, 2009; Moss and Stauning, 2012).

\section{Central Meteorological Institute at the turn of 19th and 20th centuries}

Although the network of climatological stations was becoming considerably denser at the end of the 19th century and the Institute started to issue a monthly bulletin of the Finnish climate in 1881 and daily weather reports in 1885 , the Institute still suffered from lack of competent manpower and other resources. Only one or two academic scientists were employed: their job was to run the organization, to prepare meteorological forecasts and to produce scientific papers, data bulletins and general information for the public. Some essential changes to the geophysical monitoring programmes were carried out during the first years of the 20th century. Research and measurements of hydrological conditions (snow cover and precipitation) of Finnish inland, sea level changes of coastal waters, and monitoring of marine ice, had also been allocated to the Central Meteorological Institute. Great floods in 1898-1899 in Finland caused serious damages to agriculture. Therefore better hydrological forecasts were urgently needed. However, the hydrological network was too sparse for such predictions and therefore the Finnish government allotted funds for new hydrological stations. Within a few years the number of stations were doubled but the work for running the stations was transferred to a new organization, the Hydrological Office, in 1908.

Improvement of weather forecasts and the awakening needs of aviation called for more information about the upper atmosphere. The discovery of stratosphere and tropopause as an important boundary layer in the atmosphere stimulated the research and observations of the upper atmosphere. This led to the foundation of an aerological observatory near Helsinki in 1910, as a part of the Central Meteorological Institute. Upper-air soundings were carried out there for weather predictions, initially using kites and balloons, later in the 1930s with radiosondes (Huovila, 2001). The aerological observatory was headed by Vilho Väisälä (1889-1969) in 1916-1948 (Michelsen, 2006).

Magnetic recordings at the Helsinki observatory were stopped in 1912 but there was a plan to continue them in the new aerological observatory outside the city of Helsinki. However, this proposal never realized but a new magnetic observatory was set up in northern Finland, Sodankylä, in 1913. The observatory was a part of the large-scale magnetic mapping project of the whole of Finland. The proposal for a magnetic survey came from the Russian Academy of Science in 1908. The ultimate goal of the survey was a worldwide magnetic mapping initiated by the Carnegie Institution in the USA (Simojoki, 1978). The Central Meteorological Institute managed the survey in Finland although the Sodankylä observatory was organizationally under the new Finnish Academy of Science founded in 1908. The survey programme was finalized in the late-1920s and it comprised about 1000 observations all around Finland. The results were published by Jaakko Keränen (1883-1979), who was the director of the Meteorological Institute (1931-1953) and was in charge for the magnetic measurements during the survey project (Keränen, 1933).

Finland declared its independence in 1917, and a full reorganization of public administration was started soon thereafter. In the new system the Finnish Meteorological Institute 
was transferred in 1919 from the Society of Sciences and Letters to the Ministry of Agriculture. The director of the new State Meteorological Institute was Gustaf Melander (18611938) (Fig. 4), who was one of the initiators that promoted the separation from the Society of Sciences. In addition to the organizational change of the Meteorological Institute, the Marine Research Institute, Hydrological Office and Geodetic Institute were founded as new governmental bodies.

Under the leadership of Melander, the FMI developed rapidly towards a research institute when the younger generation of scientists were qualified in their profession in various branches of meteorology as well as geomagnetism. In 1918 when the FMI was reorganized as a state research institute, the number of workers at the FMI was about 25, from which about 10 were academically educated (today the number of employees is about 700). In the beginning of the 20th century no academic chair was on meteorology at the University of Helsinki. Therefore higher education in meteorology and advanced training for various meteorological observations were attained abroad. Around the turn of the 19th and 20th centuries the institutions for further education of the scientific employees of the FMI were the Russian Academy in St. Petersburg, the Physical Observatory in Pavlovsk, and Potsdam's magnetic observatory in Germany. Practically all meteorological and geomagnetic instruments were bought from these institutions. Scientific connections and co-operations between the FMI and these institutions were close. However, the contacts with the St. Petersburg institutes were broken after the Russian revolution in 1917. Since then, a more closely co-operation between institutions of the Nordic countries were intensified.

Edited by: M. G. Johnsen

Reviewed by: R. J. Pellinen and T. L. Hansen

\section{References}

Barr, W.: The expeditions of the First International Polar Year 188383, The Arctic Institute of North America, 417 pp., 2008.

Barraclough D. R., Clark, T. D. G, Cowley, S. W. H., Hibberd, F. H., Hide, R., Kerridge, D. J., Lowes, F. J., Malin, S. R. C., Murphy, T., Rishbeth, H., Runcorn, S. K., Soffel, H. C., Stewart, D. N., Stuart, W. F., Whaler, K. A., and Winch, D. E.: 150 years of magnetic observatories: Recent research on world data, Surv. Geophys., 13, 47-88, 1992.

Cassidy, D. C.: Meteorology in Mannheim: The Palatine Meteorological Society 1780-1795, Sudhoffs Archive, 69, 1-25, 1985.

Cawood, J.: Terrestrial magnetism and the development of international collaboration in the early nineteenth century, Ann. Sci., 34, 551-572, 1977

Gauss, C. F.: Bemerkungen über die Einrichtung und den Gebrauch des Bifilar-Magnetometers, in: Resultate aus den Beobachtungen des magnetischen Vereins im Jahre 1837, edited by: Gauss, C. F. and Weber, W., 20-37, 1838.

Hentschel, K.: Gauss, Meyerstein and Hanoverian metrology, Ann. Sci., 64, 41-75, 2007.
Holmberg, P.: The history of physics in Finland 1828-1918. The History of Learning and Science in Finland 1828-1918, 5a, Societas Scientiarum Fennica, Helsinki, 267 pp., 1992.

Holmberg, P. and Nevanlinna, H.: Geomagnetism in Finland: the lasting legacy of Johan Jakob Nervander, Europhysics News 36/3, 82-85, 2005.

Huovila, S.: Meteorology, Geophysica, 37, 287-308, 2001.

Keränen, J.: A magnetic survey of Finland on July 1 1930, Finn. Met. Inst.-Stud. Earth Magn., 17, 39 pp., 1933.

Lockwood, M.: Reconstruction and prediction of variations in the open solar magnetic flux and interplanetary conditions, Living Rev. Solar Phys., 10, doi:10.12942/lrsp-2013-4, 2013.

Lockwood, M., Barnard, L., Nevanlinna, H., Owens, M. J., Harrison, R. G., Rouillard, A. P., and Davis, C. J.: Reconstruction of geomagnetic activity and near-Earth interplanetary conditions over the past $167 \mathrm{yr}$ - Part 1: A new geomagnetic data composite, Ann. Geophys., 31, 1957-1977, doi:10.5194/angeo-31-19572013, 2013.

Malin, S. R. C. and Barraclough, D. R.: Humboldt and the Earth's magnetic field, Q. J. Astr. Soc., 32, 279-293, 1991.

Michelsen, K.-E.: Global Innovator - The story of Vaisala, available at: www.vaisala.com/historybook (last access: 27 March 2014), 2006.

Moss, K. and Stauning, P.: Sophus Peter Tromholt: an outstanding pioneer in auroral research, Hist. Geo Space. Sci., 3, 53-72, doi:10.5194/hgss-3-53-2012, 2012.

Nervander, J. J.: Mémoire sur un Galvanométre, Ann. Chim. Phys., 55, 156-184, 1834.

Nevanlinna, H.: Results of the Helsinki magnetic observatory 18441912, Ann. Geophys., 22, 1691-1704, doi:10.5194/angeo-221691-2004, 2004.

Nevanlinna, H.: Founding Father of Finnish Geomagnetic Research, Transaction of AGU, EOS, 86, 325-327, 2005.

Nevanlinna, H. and Häkkinen, L.: Results of Russian geomagnetic observatories in the 19th century: magnetic activity, 1841-1862, Ann. Geophys., 28, 917-926, doi:10.5194/angeo-28-917-2010, 2010.

Seppinen, I. and Pellinen, R.: The history of Finnish space activities, Beauchesne, Paris, 203 pp., 2009.

Simojoki, H.: The history of geophysics in Finland 1828-1918. The History of Learning and Science, 5b, Societas Scientiarum Fennica, Helsinki, 157 pp., 1978.

Stern, D. P.: Millennium of geomagnetism, Rev. Geophys., 40, 130, 2002.

Svalgaard, L. and Cliver, E. W.: Interhourly variability index of geomagnetic activity and its use in deriving the long-term variation of solar wind speed, J. Geophys. Res., 112, A10111, doi:10.1029/2007JA012437, 2007.

Tietäväinen, H., Tuomenvirta, H., and Venäläinen, A.: Annual and seasonal mean temperature in Finland during the last 160 years based on gridded temperature data, Int. J. Climatol., 30, 22472256, 2010.

Venermo, J. and Sihvola, A.: The tangent galvanometer of Johan Jacob Nervander, IEEE Instru. Meas. Mag., June 2008, 16-23, 2008. 